\title{
Conversion of $\left[\mathrm{U}-{ }^{14} \mathrm{G}\right]$ Glucose into Carbon Dioxide, Glycogen, Cholesterol and Fatty Acids in Liver Slices from Embryonic and Growing Chicks
}

\author{
By ALAN G. GOODRIDGE* \\ Department of Physiology, University of Kansas Medical Center, \\ Kansas City, Kans. 66103, U.S.A.
}

(Received 31 January 1968)

\begin{abstract}
Incorporation of [U. $\left.{ }^{14} \mathrm{C}\right]$ glucose into carbon dioxide, glycogen, cholesterol and fatty acids and of ${ }^{3} \mathrm{H}_{2} \mathrm{O}$ into cholesterol and fatty acids was measured in liver slices from embryos and growing chicks. During the embryonic period, rates of incorporation were low and stable for all pathways. Fatty acid synthesis and glucose oxidation increased promptly when the chicks were fed, reaching plateau levels within 6 days. Cholesterol and glycogen synthesis increased only slightly when the birds were fed. After 5 and 11 days respectively, cholesterol and glycogen synthesis began to increase rapidly. The rate of glucose oxidation in liver slices from 4-week-old chicks was 20-fold greater than in slices of embryonic liver; glycogen, cholesterol and fatty acid synthesis had increased approximately 100-, 300 - and 1000-fold respectively. The increase in the metabolism of [U.14C]glucose that occurred after hatching was probably due to the change from a high-fat noncarbohydrate diet (yolk) to a high-carbohydrate low-fat diet (mash).
\end{abstract}

Very little is known about the development of hepatic lipogenesis in birds or mammals. Though it is known that this process is very active in slices of liver from foetal rats and rabbits during the last third of embryonic life (Villee \& Hagerman, 1958; Roux, 1966; Ballard \& Hanson, 1967), the initiation and development of lipogenesis have not been studied. At birth lipogenesis in rat and rabbit liver decreases markedly, presumably because of the high lipid content of the milk on which the newborn are nourished. Adult rates of lipogenesis are attained after weaning (Villee \& Hagerman, 1958; Ballard \& Hanson, 1967). The only information available on avian species indicates that the rate of lipogenesis in chick embryos is very low (Schoenheimer \& Rittenberg, 1936; Kilsheimer, Weber \& Ashmore, 1960).

The present paper concerns changes in the rate of hepatic lipogenesis and some related processes occurring in embryos and chicks from 16 days of incubation to 30 days after hatching. Rates of fatty acid, cholesterol and glycogen synthesis from glucose and glucose oxidation in liver slices were determined. The results indicate that the development of lipogenesis occurs rapidly after newly hatched chicks are fed and involves a 350-1000-fold increase in the rate of fatty acid synthesis.

* Present address: Banting and Best Department of Medical Research, University of Toronto, Toronto, Ont., Canada.

\section{MATERIALS AND METHODS}

Unincubated embryonated eggs from White Leghorn chickens were obtained from a commercial supplier and incubated in an electric forced-draft incubator at $37 \cdot 5 \pm 0.5^{\circ}$ and $60 \%$ relative humidity. The ages given for the embryos are the actual days of incubation.

One-day-old chicks were removed from the incubator and placed in battery brooders that had thermostatically controlled heaters and wire-mesh floors. The heating units provided no illumination. The ambient temperature of the room housing the brooders was maintained at 24-29 ${ }^{\circ}$. A photoperiod of $16 \mathrm{hr}$./day was provided. The chicks were maintained ad libitum on a diet of Purina chicken mash (Growena without antibiotic) and water. Food and water were provided immediately after the birds had been transferred to the brooders (8-10a.m. on the day after the day of hatching). Birds of both sexes were used since there were no detectable differences due to sex.

All birds were killed between 8 and 10a.m. on the day of the experiment. Embryos were removed from the eggs, freed of extra-embryonic tissue and decapitated. Chicks were killed by decapitation. One piece of the liver was removed and placed in ice-cold $0.9 \% \mathrm{NaCl}$. Pieces of liver from as many as four birds were pooled, depending on the size of the animals. Liver $\mathbf{N}$ content was calculated from the $\mathrm{N}$ concentration (micro-Kjeldahl technique; Frerichs \& Ball, 1962) of $10 \%(w / v)$ homogenates (in $0.25 \mathrm{M}$-sucrose) prepared from the remaining liver (the homogenates were used for the enzyme assays reported in the next paper; Goodridge, 1968b).

Liver slices (approx. 250mg.) prepared with a StadieRiggs microtome were blotted on filter paper, weighed on a 
torsion balance and placed in $25 \mathrm{ml}$. flasks containing $5 \cdot 0 \mathrm{ml}$. of medium. The flasks were gassed with $\mathrm{O}_{2}+\mathrm{CO}_{2}(95: 5)$ (21./min. for $1 \mathrm{~min}$.), sealed with serum stoppers fitted with disposable polyethylene centre wells (Kontes Glass Inc., Vineland, N.J., U.S.A.) and incubated for $1 \mathrm{hr}$. at $40^{\circ}$ in a metabolic shaker (110 cyc./min.). The incubation medium was a modified Krebs-Ringer bicarbonate buffer with onehalf the recommended amount of $\mathrm{CaCl}_{2}$ (Umbreit, Burris \& Stauffer, 1964) and with $125 \mathrm{~mm}-\mathrm{K}^{+}$and $25 \mathrm{~mm}-\mathrm{Na}^{+}$ (Flink, Hastings \& Lowry, 1950). [U-14C]Glucose (11 mM, $0.5 \mu \mathrm{c} / \mathrm{ml}$.) was added as substrate. In all but a few experiments the medium was enriched with $1 \mathrm{mc}$ of ${ }^{3} \mathrm{H}_{2} \mathrm{O}$.

At the end of the incubation period, $\mathrm{CO}_{2}$ was collected in Hyamine hydroxide (Packard Instrument Co. Inc., Downers Grove, Ill., U.S.A.) as previously described (Goodridge, 1968a). The Hyamine was dissolved in $15 \mathrm{ml}$. of a toluene-ethanol $(4: 1, \mathrm{v} / \mathrm{v})$ scintillation fluid containing 2,5-diphenyloxazole $(0 \cdot 4 \%)$ and 1,4-bis-(5-phenyloxazol2-yl)benzene (0.01\%).

The liver slices were washed with $0.9 \% \mathrm{NaCl}$ and homogenized in chloroform-methanol $(1: 1, v / v)$. The insoluble material was collected by centrifugation and re-extracted with chloroform-methanol. The insoluble material was dried and digested in $40 \%(\mathrm{w} / \mathrm{v}) \mathrm{KOH}$. After the addition of $2 \mathrm{mg}$. of carrier glycogen, total glycogen was precipitated from the $\mathrm{KOH}$ digest with $1.25 \mathrm{vol}$. of $95 \%(\mathrm{v} / \mathrm{v})$ ethanol (Good, Kramer \& Somogyi, 1933). The precipitate was collected by centrifugation and dissolved in $0.9 \% \mathrm{NaCl}$. Glycogen was reprecipitated from the $\mathrm{NaCl}$ solution,

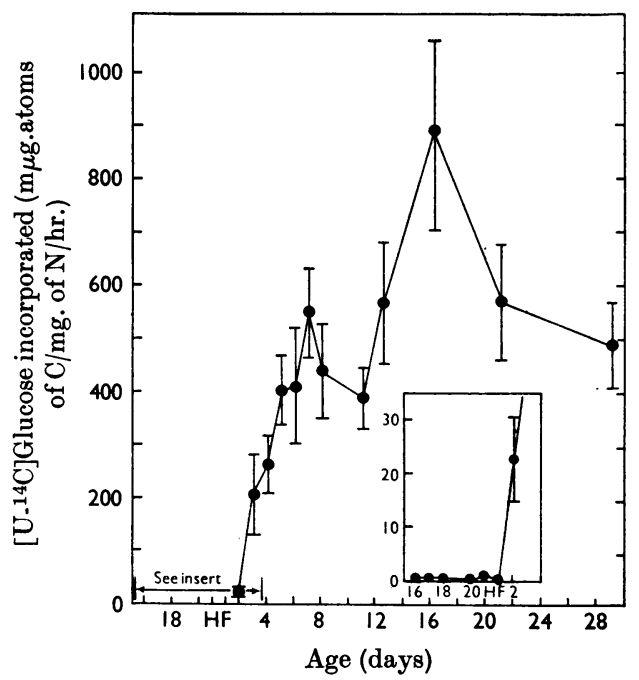

Fig. 1. Incorporation of [U-14C]glucose into total fatty acids. Each point represents the average of four to 11 experiments [some experiments represent the averages of pooled (two to four) tissue samples]. The vertical bars indicate S.E.M. (the lack of a vertical bar indicates that the S.E.M. was too small to put on the graph). Numbers to the left of $\mathbf{H}$ on the abscissa refer to days of incubation; those to the right refer to age of chicks. $H$ indicates the day of hatching; $F$ indicates the day of first feeding. collected by centrifugation and washed successively with 95\% ethanol and acetone. The washed precipitate was hydrolysed in $2 \mathrm{ml}$. of $2 \mathrm{~N}-\mathrm{HCl}$ at $100^{\circ}$ for $1 \mathrm{hr}$. A $0.2 \mathrm{ml}$. sample of the hydrolysate was added directly to $15 \mathrm{ml}$. of scintillation fluid and $1 \mathrm{ml}$. of ethanol for counting.

The combined chloroform-methanol extracts were adjusted to a chloroform-methanol concentration ratio of $2: 1(v / v)$ and processed by the 'salty-wash' method of Folch, Lees \& Sloane-Stanley (1957) to remove non-lipid radioactive material. Total lipids were saponified with ethanolic $\mathrm{KOH}$ and the non-saponifiable material was extracted into light petroleum (b.p. 37-54 ${ }^{\circ}$. The digitonide of cholesterol was isolated from an acetone-ethanol $(1: 1$, $\mathrm{v} / \mathrm{v}$ ) solution of the non-saponifiable material (Sperry, 1963). The digitonide was collected by centrifugation, washed successively with acetone and light petroleum (b.p. 37-54 ${ }^{\circ}$ ), dried, dissolved in $1 \mathrm{ml}$. of hot acetic acid and rinsed into a scintillation vial with $15 \mathrm{ml}$. of scintillation fluid.

Fatty acids were extracted from the saponified mixture as described by Goodridge \& Ball (1967b), and dissolved in scintillation fluid.

Radioactivity was measured in a three-channel Packard Tri-Carb liquid-scintillation spectrometer. Corrections for spillage of ${ }^{14} \mathrm{C}$ radioactivity into the ${ }^{3} \mathrm{H}$ channel, quenching and efficiency of the scintillation spectrometer were determined by external standardization.

The ${ }^{3} \mathrm{H}_{2} \mathrm{O}$ and [U.14C]glucose were purchased from New England Nuclear Corp., Boston, Mass., U.S.A. Statistical significance of the data was tested where appropriate by the Mann-Whitney test (Siegel, 1956). Standard errors are provided to indicate the degree of variance in the data.

\section{RESULTS}

Hepatic fatty acid and cholesterol synthesis. The rate of fatty acid synthesis was estimated by measuring the incorporation of $\left[\mathrm{U}-{ }^{14} \mathrm{C}\right]$ glucose

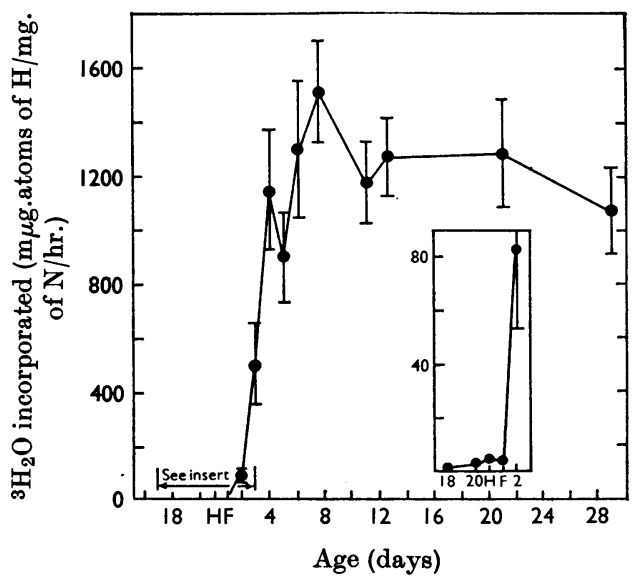

Fig. 2. Incorporation of ${ }^{3} \mathrm{H}_{2} \mathrm{O}$ into total fatty acids (it being assumed that neither ${ }^{1} \mathrm{H}$ nor ${ }^{3} \mathrm{H}$ of water is preferentially incorporated during lipogenesis). Each point represents the average of four to ten experiments. For further explanation see the legend to Fig. 1. 
(Fig. 1) and ${ }^{3} \mathrm{H}_{2} \mathrm{O}$ (Fig. 2) into fatty acids. Fatty acid synthesis was very low during the embryonic period, but increased rapidly after the chicks were fed. In liver slices from embryos incorporation of [U. ${ }^{14} \mathrm{C}$ ] glucose varied from 0.5 to $0.8 \mathrm{~m} \mu$ g.atom of $\mathrm{C} / \mathrm{mg}$. of $\mathrm{N} / \mathrm{hr}$., and that of ${ }^{3} \mathrm{H}_{2} \mathrm{O}$ from $1 \cdot 7$ to $4.4 \mathrm{~m} \mu$ g.atoms of $\mathrm{H} / \mathrm{mg}$. of $\mathrm{N} / \mathrm{hr}$. Both rates were slightly lower in 1-day-old unfed chicks than in dayof-hatching chicks. After $24 \mathrm{hr}$. of feeding, [U-14C]glucose incorporation increased to $23 \mathrm{~m} \mu$ g.atoms of $\mathrm{C} / \mathrm{mg}$. of $\mathrm{N} / \mathrm{hr}$. (58-fold) and ${ }^{3} \mathrm{H}_{2} \mathrm{O}$ incorporation to $83 \mathrm{~m} \mu$ g.atoms of $\mathrm{H} / \mathrm{mg}$. of $\mathrm{N} / \mathrm{hr}$. (23-fold). The rate of fatty acid synthesis continued to increase until the chicks were 7-8 days old, after which a plateau occurred where the incorporation of [U-14C] glucose was $500-600 \mathrm{~m} \mu$ g.atoms of $\mathrm{C} / \mathrm{mg}$. of $\mathrm{N} / \mathrm{hr}$. or about 1000 times the rate in embryonic liver slices, and the incorporation of ${ }^{3} \mathrm{H}_{2} \mathrm{O}$ was about $1300 \mathrm{~m} \mu$ g.atoms of $\mathrm{H} / \mathrm{mg}$. of $\mathrm{N} / \mathrm{hr}$. or about 350 times the rate in liver slices from embryos.

Development of the synthesis of cholesterol in liver slices was estimated by measuring simultaneously the incorporation of [U.14C]glucose and of ${ }^{3} \mathrm{H}_{2} \mathrm{O}$ into cholesterol (Figs. 3 and 4). Cholesterol synthesis was very low in livers from embryos and chicks up to the age of 5 days. From 6 to 30 days of age hepatic cholesterol synthesis increased markedly, incorporation of $\left[\mathrm{U} \cdot{ }^{14} \mathrm{C}\right]$ glucose increasing 40 -fold and that of ${ }^{3} \mathrm{H}_{2} \mathrm{O} 20$-fold.

Liver slices from chicks with low and high rates of lipogenesis (day-of-hatching and 13-day-old chicks respectively) were incubated in media containing 11,22 and $44 \mathrm{~mm}$ concentrations of glucose to determine the effect of glucose concentration on the rates of cholesterol and fatty acid

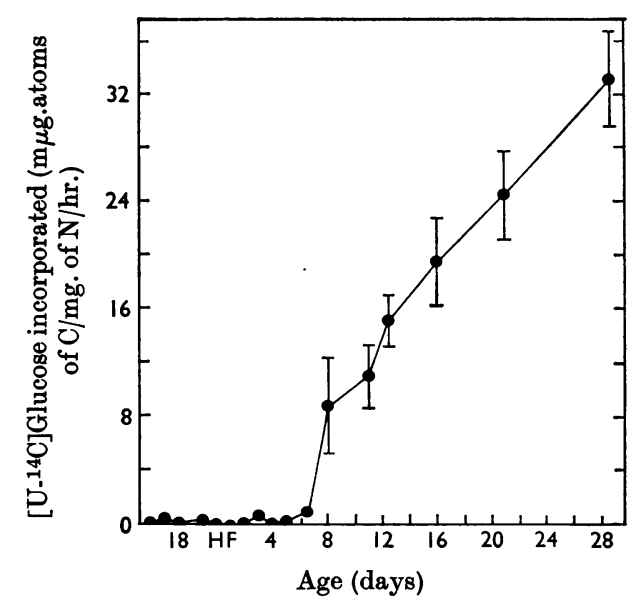

Fig. 3. Incorporation of [U-14C]glucose into cholesterol. Expression of data and numbers of experiments are the same as in Fig. 1. synthesis. Rates of incorporation of both [U-14C]glucose and ${ }^{3} \mathrm{H}_{2} \mathrm{O}$ were used as measures of fatty acid synthesis by liver slices from both age groups. The results (Table 1) show no sign of dependence of the rate of fatty acid synthesis on glucose concentration within the range tested if ${ }^{3} \mathrm{H}_{2} \mathrm{O}$ incorporation was used as the rate indicator. In general, the incorporation of $\left[\mathrm{U}-{ }^{14} \mathrm{C}\right]$ glucose showed a similar independence of the concentration of glucose. The only exception was a higher rate of incorporation in liver slices from day-of-hatching chicks in the $44 \mathrm{~mm}$-glucose medium. Since ${ }^{3} \mathrm{H}_{2} \mathrm{O}$ incorporation was unaffected, the increase in $\left[\mathrm{U} \cdot{ }^{14} \mathrm{C}\right]$ glucose incorporation suggested an increase in the ${ }^{14} \mathrm{C}$ specific radioactivity of a fatty acid precursor. Rates of cholesterol synthesis at different glucose concentrations were measured only in the tissues of 13-day-old chicks, in which there was no indication of a dependence on glucose concentration. Cholesterol synthesis in tissue from day-of-hatching chicks was not tested because the rates were too low.

Hepatic glucose oxidation and glycogen synthesis. Developmental changes in the oxidation of glucose (Fig. 5) followed a pattern similar to that observed for fatty acid synthesis. The mean rates of glucose oxidation were low and changed little in livers from embryos and newly hatched unfed chicks (100$190 \mathrm{~m} \mu$ g.atoms of glucose $\mathrm{C}$ incorporated $/ \mathrm{mg}$. of $\mathrm{N} / \mathrm{hr}$.). At $24 \mathrm{hr}$. after the chicks were given food the rate increased to $620 \mathrm{~m} \mu$ g.atoms of $\mathrm{C} / \mathrm{mg}$. of

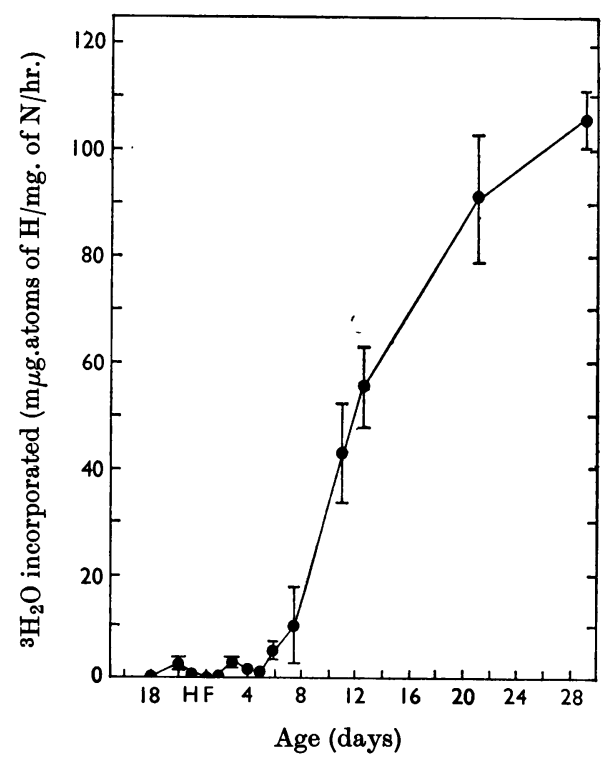

Fig. 4. Incorporation of ${ }^{3} \mathrm{H}_{2} \mathrm{O}$ into cholesterol. Expression of data and numbers of experiments are the same as in Fig. 2. 
Table 1. Effect of glucose concentration on incorporation of $\left[\mathrm{U}-{ }^{14} \mathrm{C}\right]$ glucose into carbon dioxide, glycogen, cholesterol and fatty acids and of ${ }^{3} \mathrm{H}_{2} \mathrm{O}$ into cholesterol and fatty acids in liver slices from 13-day-old and day-of-hatching chicks

The values in parentheses are rates of incorporation of [U.14C]glucose or ${ }^{3} \mathrm{H}_{2} \mathrm{O}$ in $\mathrm{m} \mu \mathrm{g}$.atoms of $\mathrm{C} \mathrm{or} \mathrm{H} / \mathrm{mg}$. of $\mathrm{N} / \mathrm{hr}$. All results are expressed as means \pm s.E.M. of either six experiments (13-day-old chicks) or four experiments (day-of-hatching chicks).

Chicks

13-day-old

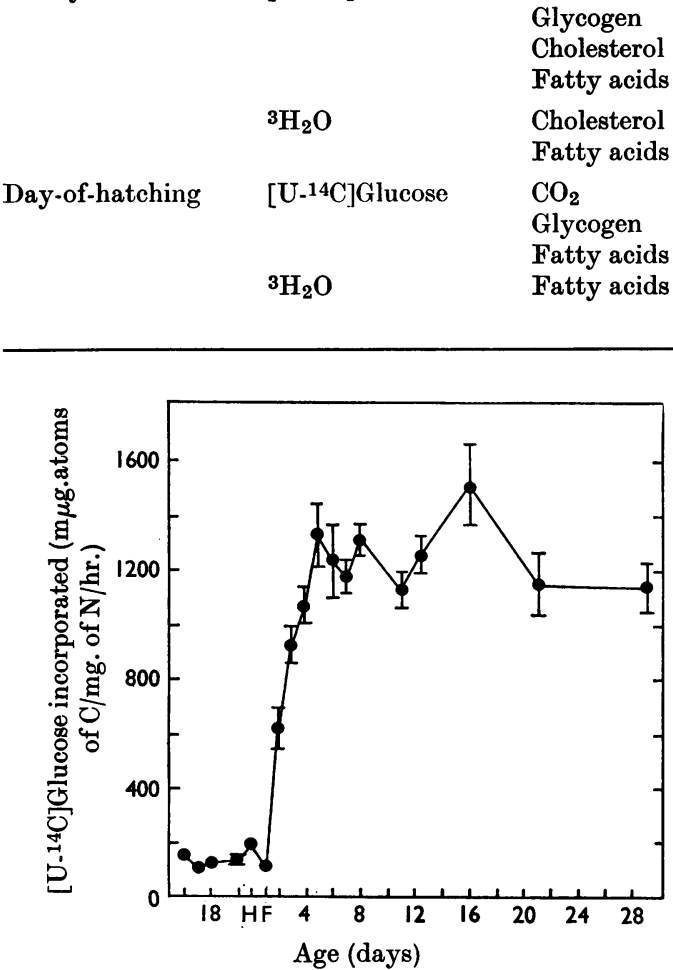

Fig. 5. Incorporation of $\left[\mathrm{U}_{-14}{ }^{14} \mathrm{C}\right] \mathrm{glucose}$ into $\mathrm{CO}_{2}$. Expression of data and numbers of experiments are the same as in Fig. 1.

$\mathrm{N} / \mathrm{hr}$. After 4 days of feeding (5-day-old chicks) glucose oxidation increased to $1320 \mathrm{~m} \mu \mathrm{g}$.atoms of $\mathrm{C} / \mathrm{mg}$. of $\mathrm{N} / \mathrm{hr}$. and stayed at that level throughout the remainder of the observation period.

Of the four metabolic pathways examined in livers of developing chicks, glycogen synthesis was observed to be the most variable (Fig. 6). Mean rates of glycogen synthesis in liver slices from embryos varied from 6.3 to $9.4 \mathrm{~m} \mu$ g.atoms of glucose $C$ incorporated $/ \mathrm{mg}$. of $\mathrm{N} / \mathrm{hr}$. (i.e. more than ten times the rate for fatty acid synthesis). The rate of glycogen synthesis was $1 \cdot 7 \pm 0 \cdot 3 \mathrm{~m} \mu$ g.atoms of
Incorporation (\% of rate with $11 \mathrm{~mm}$-glucose)

\begin{tabular}{lcc}
\hline \multicolumn{1}{c}{$11 \mathrm{mM}$} & $22 \mathrm{mM}$ & $44 \mathrm{mM}$ \\
& & \\
$100(1260 \pm 90)$ & $120 \pm 10$ & $140 \pm 16$ \\
$100(200 \pm 90)$ & $400 \pm 130$ & $1280 \pm 540$ \\
$100(17 \pm 2)$ & $124 \pm 23$ & $138 \pm 33$ \\
$100(700 \pm 160)$ & $140 \pm 25$ & $185 \pm 47$ \\
$100(63 \pm 9)$ & $81 \pm 13$ & $80 \pm 12$ \\
$100(1240 \pm 140)$ & $105 \pm 16$ & $106 \pm 19$ \\
$100(122 \pm 7)$ & $129 \pm 7$ & $187 \pm 13$ \\
$100(9 \cdot 7 \pm 1 \cdot 1)$ & $148 \pm 25$ & $300 \pm 60$ \\
$100(0 \cdot 3 \pm 0 \cdot 01)$ & $109 \pm 15$ & $270 \pm 39$ \\
$100(5 \cdot 5 \pm 0 \cdot 4)$ & $83 \pm 6$ & $96 \pm 19$
\end{tabular}

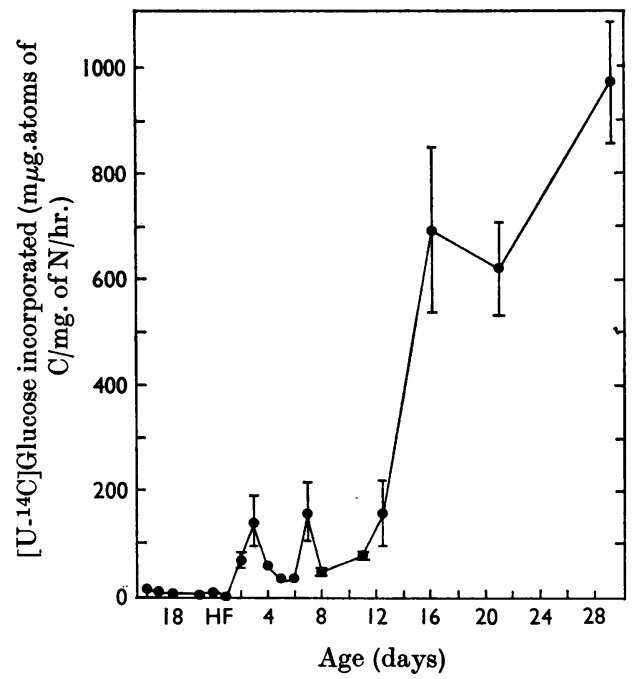

Fig. 6. Incorporation of $\left[\mathrm{U}-{ }^{14} \mathrm{C}\right] \mathrm{glucose}$ into glycogen. Expression of data and numbers of experiments are the same as in Fig. 1.

glucose $\mathrm{C}$ incorporated $/ \mathrm{mg}$. of $\mathrm{N} / \mathrm{hr}$. in liver from 1-day-old unfed chicks, a decrease of $75 \%$ from the rate for day-of-hatching chicks. At $24 \mathrm{hr}$. after initiation of feeding, glycogen synthesis increased to $68 \pm 20 \mathrm{~m} \mu$ g.atoms of glucose $\mathrm{C}$ incorporated $/ \mathrm{mg}$. of $\mathrm{N} / \mathrm{hr}$., and after 2 days there was a further increase in the mean rate and an increase in variability. The third day of feeding resulted in a decline in glycogen synthesis to about the rate observed after 
1 day of feeding. This decline continued for the next 2 days, reaching a rate one-half of that for livers from chicks fed for 1 day. A large but highly variable increase was observed in livers from 7-day. old chicks, followed by another decrease in glycogen synthesis in tissue from 8-day-old chicks. Beginning in livers from 11-day-old chicks there was a progressive increase in glycogen synthesis, which reached $960 \pm 100 \mathrm{~m} \mu$ g.atoms of glucose $C$ incorporated/mg. of $\mathrm{N} / \mathrm{hr}$. in tissue from 28-30-dayold chicks. Though no plateau was observed, there were no statistically significant differences after the chicks were 16 days old.

The effect of glucose concentration on the rates of incorporation of glucose carbon into carbon dioxide and glycogen was also tested (Table 1). The pattern was the same as that observed for incorporation into cholesterol and fatty acids except for glycogen synthesis in liver slices from the 13-day-old chicks. Here increasing the glucose concentration resulted in a marked enhancement of the incorporation of glucose carbon into glycogen. The data suggest that all of the pathways measured (except glycogen synthesis in the older chicks) were operating at or near maximum rate at a glucose concentration of $11 \mathrm{~mm}$ (cf. Cahill, Hastings, Ashmore \& Zottu, 1958).

Hepatic nitrogen content. The general pattern of metabolic changes observed in this study would be the same if the data were expressed on a wet-weight or body-weight basis. Nitrogen content of chick liver was fairly constant during the period of observation, with mean values varying from $2 \cdot 4$ to $3 \cdot 0 \mathrm{mg}$. of $\mathrm{N} / 100 \mathrm{mg}$. wet wt.

\section{DISCUSSION}

The combined use of ${ }^{3} \mathrm{H}_{2} \mathrm{O}$ and [U-14 $\mathrm{C}$ ]glucose permits a direct evaluation of the accuracy of the incorporation of $\left[\mathrm{U} \cdot{ }^{14} \mathrm{C}\right]$ glucose as a measure of fatty acid and cholesterol synthesis. Fatty acids synthesized in the presence of ${ }^{2} \mathrm{H}_{2} \mathrm{O}$ or ${ }^{3} \mathrm{H}_{2} \mathrm{O}$ have isotopic label incorporated into stable linkages at both odd- and even-numbered carbon atoms (Rittenberg \& Schoenheimer, 1937; Foster \& Bloom, 1963). Isotopic label is also incorporated into cholesterol during its biosynthesis (Rittenberg \& Schoenheimer, 1937). There is no incorporation of isotopic label into preformed lipids. Owing to the high concentration of water in the incubating medium, the specific radioactivity of the hydrogen being incorporated into lipids is very stable, despite large variations in the rates of lipid synthesis and other metabolic pathways. Isotope dilution is a serious problem with the more commonly used technique of using [U.14C]glucose incorporation to measure lipid synthesis. Particularly subject to

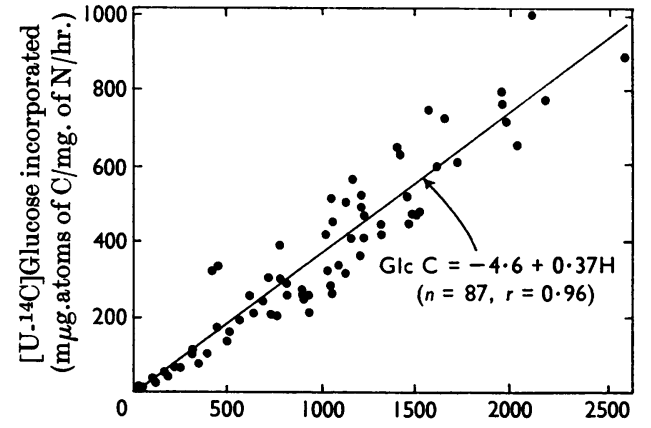

${ }^{3} \mathrm{H}_{2} \mathrm{O}$ incorporated ( $\mathrm{m} \mu$ g.atoms of $\mathrm{H} / \mathrm{mg}$. of $\mathrm{N} / \mathrm{hr}$.)

Fig. 7. Relationship between incorporation of [U.14C]glucose into fatty acids and incorporation of ${ }^{3} \mathrm{H}_{2} \mathrm{O}$ into fatty acids in liver slices from chicks at various ages. The straight line was calculated by the method of least squares. Rates of incorporation in liver slices from embryos and unfed chicks were too low to be plotted, but they were included in the calculation of the straight line and the correlation coefficient. The equation for the line was Glc $\mathrm{C}=-\mathbf{4 \cdot 6 +}$ $0 \cdot 37 \mathrm{H}$, where ' $\mathrm{Glc} \mathrm{C}$ ' and ' $\mathrm{H}$ ' represent rates of incorporation of glucose carbon and tritium respectively. The correlation coefficient, $r$, was 0.96 .

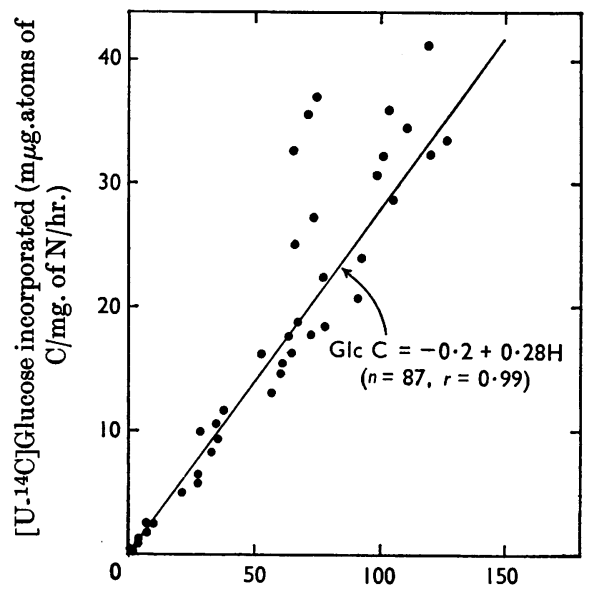

${ }^{3} \mathrm{H}_{2} \mathrm{O}$ incorporated ( $\mathrm{m} \mu$ g.atoms of $\mathrm{H} / \mathrm{mg}$. of $\mathrm{N} / \mathrm{hr}$.)

Fig. 8. Relationship between incorporation of [U-14C]glucose into cholesterol and incorporation of ${ }^{3} \mathrm{H}_{2} \mathrm{O}$ into cholesterol in liver slices from chicks at various ages. The straight line was calculated by the method of least squares. Most of the rates of incorporation in liver slices from embryos and chicks less than 5 days old were too low to be plotted, but they were included in the calculation of the straight line and the correlation coefficient. The equation for the line was Gle $\mathrm{C}=-\mathbf{0 . 2}+\mathbf{0} \cdot 28 \mathrm{H}$, where ' $\mathrm{Glc} \mathrm{C}$ ' and ' $H$ ' represent rates of incorporation of glucose carbon and tritium respectively. The correlation coefficient, $r$, was 0.99 . 
dilution by unlabelled compounds are the metabolic intermediates (between glucose and fatty acids) that may be present in the tissues in small concentrations.

The relationship between the incorporation of [U-14 $\mathrm{C}$ ]glucose and the incorporation of ${ }^{3} \mathrm{H}_{2} \mathrm{O}$ into fatty acids in liver slices is shown in Fig. 7. A similar relationship for incorporation into cholesterol is shown in Fig. 8. The simple linear relationships between these two measures of fatty acid and cholesterol synthesis suggest that the rate of production of acetyl-CoA (specifically, that pool of acetyl-CoA which serves as a precursor for lipid synthesis; cf. Fritz, 1967) from non-radioactive substrates (e.g. glycogen or amino acids) was low compared with the rate of production of acetyl-CoA from glucose of the medium. Given the relationships just described, appreciable isotope dilution could have occurred only if the rate of production of the unlabelled acetyl-CoA increased in precisely the same way as fatty acid and cholesterol synthesis during the first 4 weeks after hatching. This was impossible because the increase in fatty acid synthesis was essentially complete before cholesterol synthesis began to increase appreciably. Therefore rates of incorporation of glucose carbon into fatty acids and cholesterol seem to provide accurate estimates of the rates of fatty acid and cholesterol synthesis in liver slices from growing chicks.

Rates of incorporation of ${ }^{14} \mathrm{C}$ and ${ }^{3} \mathrm{H}$ in slices of liver from embryos and unfed chicks were included in the above calculations, but were too low to be plotted in Figs. 7 and 8. When these low values were analysed separately, no correlation existed between rates of incorporation of the two isotopic labels. In these liver slices the ${ }^{3} \mathrm{H}$ incorporated/glucose $\mathrm{C}$ incorporated ratio was higher than in tissue from the older chicks. This lack of correlation may indicate isotope-dilution effects or, particularly in cholesterol synthesis, may reflect the technical difficulties inherent in trying to measure the very low amounts of radioactivity. The fact that in liver slices from day-of-hatching chicks increasing the glucose concentration increased incorporation of [U-14C]glucose into fatty acids, but not incorporation of ${ }^{3} \mathrm{H}_{2} \mathrm{O}$, supports the notion of isotope dilution in livers with low rates of synthesis.

The development of lipogenesis in chick liver conformed rather well to expectations based on the known effects of dietary fat and carbohydrate on lipogenesis (Masoro, 1962). The yolk on which the embryo is nourished has a high fat content and is essentially carbohydrate-free. Since high-fat lowcarbohydrate diets inhibit lipogenesis (Masoro, Chaikoff, Chernick \& Felts, 1950), it was not surprising to find a very low rate of fatty acid synthesis in embryonic liver, as previously reported by Schoenheimer \& Rittenberg (1936) and
Kilsheimer et al. (1960). The newly hatched chicks were fed on a mash diet that was relatively high in carbohydrate (approx. $70 \%$ by wt.) and low in fat (approx. 3\% by wt.). Consequently an increase in lipogenesis was expected when the chicks were fed. The promptness and magnitude of the response, however, were somewhat surprising, especially since chick liver is high in fatty acids and cholesterol during the first week after hatching (Entenman, Lorenz \& Chaikoff, 1940), a condition often associated with depressed lipogenesis in other species (Masoro, 1962). It should be noted here that lipogenesis does not develop if the birds are starved (Goodridge, 1968c).

The development of lipogenesis in rat liver is similar to that of the chick in that most of the changes can be predicted from the dietary conditions (Ballard \& Hanson, 1967). During foetal life and after weaning the rat's diet is basically high in carbohydrate and low in fat. Lipogenesis is high during these periods. During the suckling period the diet is high in fat; lipogenesis is low. Unlike the situation in chick liver, however, the initial development of lipogenesis in foetal rat liver is not under the influence of a change in the diet (Villee \& Hagerman, 1958). At present there are no data to indicate what factors do initiate lipogenesis in foetal rat liver.

The increase in glucose oxidation that accompanies the increase in lipogenesis in chick liver slices suggests that the increase in lipogenesis is associated with, and may be secondary to, an increase in the catabolism of glucose. Lipogenesis is closely linked to glucose catabolism in rat liver (Masoro, 1962). However, the increases in cholesterol and glycogen synthesis that occur at about 1 week of age do not seem to be explicable in terms of an increased metabolism of glucose. The delayed increase in the synthesis of cholesterol and glycogen may be related to the high hepatic concentrations of cholesterol and fatty acids that occur at the time of hatching and decrease rapidly thereafter (Entenman et al. 1940; Moore \& Doran, 1962; Feldman \& Grantham, 1964). If so, the prompt response of fatty acid synthesis and glucose oxidation to feeding is all the more surprising. The delayed increase in the synthesis of cholesterol also demonstrates that fatty acid synthesis and cholesterol synthesis need not necessarily change together.

All of the metabolic pathways measured in these experiments were very active in livers from 4-weekold chicks. Fatty acid synthesis in chick liver slices was 100 times the rate reported for liver slices from adult rats incubated under essentially identical conditions (Cahill et al. 1958; Ballard \& Hanson, 1967). The difference was even greater if chick liver was compared with liver from 4-week-old rats (Ballard \& Hanson, 1967). In 7-9-week-old pigeon 
liver incorporation of glucose carbon into fatty acids was only $20 \%$ of that observed for liver from 4-week-old chicks (Goodridge \& Ball, 1967c). A comparison of the metabolism of glucose in liver slices from rats and chicks reveals that glucose oxidation, glycogen synthesis and cholesterol synthesis were 20, four and 11 times as high respectively in chick liver as in rat liver (Cahill et al. 1958; Ballard \& Hanson, 1967). In slices of pigeon liver glycogen synthesis was roughly comparable with that observed in chick liver slices (Goodridge \& Ball, 1967c).

A greater overall rate of glucose catabolism is not the only difference in the metabolism of liver slices from chicks and rats. In rat liver fatty acid synthesis accounts for only $0.5 \%$ of the glucose carbon incorporated into carbon dioxide, glycogen, fatty acid and cholesterol (Cahill et al. 1958; Ballard \& Hanson, 1967). In chick liver fatty acid synthesis accounted for $19 \%$ of the total. Though there were differences with respect to some of the other pathways also, none was so great as the difference in fatty acid synthesis.

In rats and certain other mammals fatty acid synthesis occurs in both liver and adipose tissue with the latter tissue playing a dominant role (Cahill \& Renold, 1965). The high rate of lipogenesis in chick liver slices emphasizes the importance of liver in the synthesis of fatty acids in the chick. On a nitrogen basis, fatty acid synthesis from glucose was more than tenfold higher in liver slices (high-K ${ }^{+}$ buffer) than in intact adipose tissue (regular Krebs-Ringer bicarbonate buffer) in 7-day-old chicks and 160-fold higher in 28-30-day-old chicks (Goodridge, 1968a). If both tissues were taken from the same animals ( 16 days old) and incubated in the high- $\mathrm{K}^{+}$buffer the difference was 230 -fold in favour of liver $(n=4)$. The magnitude of the lipogenic response to feeding provides further evidence for the importance of liver in the synthesis of fatty acids. Incorporation of glucose carbon into fatty acids was 1000-fold greater in liver slices from 7-day-old chicks than in slices from embryos. There was only a 14-fold difference in adipose tissue (Goodridge, 1968a). These results suggest that in the chick, as in the pigeon (Goodridge \& Ball, 1966, $1967 a$ ), adipose tissue plays a very minor role in the synthesis of fatty acids, serving largely as a depository for fat synthesized in the liver.

I am grateful to Mrs Ellen Martens, Miss Dolores Olsen and Mr Stephen Ash for technical assistance, and to DrG.N. Loofbourrow for helpful criticism during the writing of the manuscript. This work was supported by Grant P-426 from the American Cancer Society.

\section{REFERENCES}

Ballard, F. J. \& Hanson, R. W. (1967). Biochem. J. 102, 952.

Cahill, G. F., jun., Hastings, A. B., Ashmore, J. \& Zottu, S. (1958). J. biol. Chem. 230, 125.

Cahill, G. F., jun. \& Renold, A. E. (1965). In Handbook of Physiology, Section 5: Adipose Tissue, p. 681. Ed. by Cahill, G. F., jun. \& Renold, A. E. Washington, D.C.: American Physiological Society.

Entenman, C., Lorenz, F. W. \& Chaikoff, I. L. (1940). J. biol. Chem. 133, 231.

Feldman, G. L. \& Grantham, G. K. (1964). Poult. Sci. 43, 150.

Flink, E. B., Hastings, A. B. \& Lowry, J. K. (1950). Amer. J. Physiol. 163, 598.

Folch, J. M., Lees, M. \& Sloane-Stanley, G. H. (1957). J. biol. Chem. 206, 171.

Foster, D. W. \& Bloom, B. (1963). J. biol. Chem. 238, 888.

Frerichs, H. \& Ball, E. G. (1962). J. biol. Chem. 209, 619.

Fritz, I. B. (1967). Perspect. Biol. Med. 10, 643.

Good, C. A., Kramer, H. \& Somogyi, M. (1933). J. biol. Chem. 100, 485.

Goodridge, A. G. (1968a). Amer. J. Physiol. 214, 897.

Goodridge, A. G. (1968b). Biochem. J. 108, 663.

Goodridge, A. G. (1968c). Biochem. J. 108, 667.

Goodridge, A. G. \& Ball, E. G. (1966). Amer. J. Physiol. 211, 803.

Goodridge, A. G. \& Ball, E. G. (1967a). Amer. J. Physiol. 213, 245.

Goodridge, A. G. \& Ball, E. G. (1967b). Biochemistry, 6, 1676.

Goodridge, A. G. \& Ball, E. G. (1967c). Biochemistry, 6, 2335.

Kilsheimer, G. S., Weber, D. R. \& Ashmore, J. (1960). Proc. Soc. exp. Biol., N.Y., 194, 515.

Masoro, E. J. (1962). J. Lipid Res. 3, 149.

Masoro, E. J., Chaikoff, I. L., Chernick, S. S. \& Felts, J. M. (1950). J. biol. Chem. 185, 845.

Moore, J. H. \& Doran, B. M. (1962). Biochem. J. 84, 506.

Rittenberg, D. \& Schoenheimer, R. (1937). J. biol. Chem. 121, 235.

Roux, J. F. (1966). Metabolism, 15, 856.

Schoenheimer, R. \& Rittenberg, D. (1936). J. biol. Chem. 114, 381.

Siegel, S. (1956). Nonparametric Statistics for the Behavioral Sciences, p. 312. New York: McGraw-Hill Book Co.

Sperry, W. M. (1963). J. Lipid Res. 4, 221.

Umbreit, W. W., Burris, R. H. \& Stauffer, S. F. (1964). Manometric Techniques, 4th ed., p. 312. Minneapolis: Burgess Publishing Co.

Villee, C. A. \& Hagerman, D. D. (1958). Amer. J. Physiol. 194, 457. 